\title{
Management of mass casualties due to COVID-19: handling the dead
}

\author{
Patrizio Petrone ${ }^{1}$ (D) . D’Andrea K. Joseph ${ }^{1} \cdot$ Ricardo A. Jacquez $^{1} \cdot$ Gerard A. Baltazar $^{1} \cdot$ Collin E. M. Brathwaite $^{1}$
}

Received: 11 February 2021 / Accepted: 26 May 2021 / Published online: 5 June 2021

(c) Springer-Verlag GmbH Germany, part of Springer Nature 2021

\begin{abstract}
A high number of fatalities can occur during major disasters or during events like the COVID-19 pandemic. In a natural disaster, the dead must be removed from disaster sites while rescue work is in progress; otherwise, the health and safety of the community are threatened. The COVID-19 pandemic is analogous to a natural disaster with mass casualties where the disaster sites are hospitals with morgues that are overwhelmed. As the number of the deceased rise rapidly and hospital morgues are at their full capacity, hospitals use what is called a Body Collection Point (BCP). BCP is defined as a temporary refrigeration unit used to store decedents until transport is arranged. Decedents should always be handled in a manner denoting respect, and provisions and management of resources should be properly mobilized to ensure this. Contingency plans must be created to prepare for worsening of the disaster that further overwhelms the capacity of the health care systems.
\end{abstract}

Keywords Mass casualties · COVID-19 $\cdot$ Morgues $\cdot$ Body collection point

\section{Introduction}

A considerable number of fatalities might occur during a major disaster or events such as the COVID-19 pandemic. When it becomes necessary to remove dead bodies from disaster sites because rescue work is in progress and the health and safety of the community are threatened, or where the hospital morgues are at full capacity, specific procedures must be followed [1]. In those situations, both communication and transportation may be disrupted. Therefore, it is important that action be taken to ensure the safe handling and storage of decedents until the appropriate or designated personnel can respond. In the event of a major disaster, it may be several days before the dead can be collected and processed by the Office of Medical Examiner (OME).

Patrizio Petrone

patrizio.petrone@nyulangone.org;

patrizio.petrone@gmail.com

1 Department of Surgery, NYU Langone Hospital-Long Island, NYU Long Island School of Medicine, 222 Station Plaza North, Suite 300, Mineola, NY 11501, USA

\section{Management of casualties}

The first step is to locate the deceased. In cases of major disaster, safe removal of the decedent is paramount. If safe removal is not possible because of structural damage or debris, the area should be marked, preferably via a spraypainted arrow clearly denoting the location of a decedent. If the body or body parts can be removed, then body-wrapping procedures are initiated before taking it to the fatality collection area. Examples of fatality collection areas are cement parking structures, covered areas, nearby parks, etc., which are all placed in areas separate from the supplies (i.e., body bags, disinfectants, indelible markers) - adequate amount of supplies should be kept on hand in anticipation of several possible fatalities. Infection control precautions must be always followed, for example using rubber or heavy-duty leather gloves, facemasks, and protective clothing such as a plastic apron. Hand-washing with antiseptic solution after handling decedents is essential $[1,2]$.

Personal effects must not be removed from the decedent at any time since keeping these effects with the decedent may help with identification. The body must be secured in a plastic or vinyl body bag. If a body bag is not available, the body may be wrapped in a plastic sheet approximately 4 feet $\times 10$ feet $(1.20 \mathrm{~m} \times 3 \mathrm{~m} \times 0.25 \mathrm{~mm}$ in thickness $)$ : the body is placed in the center of the sheet and secured in such a manner that fluids are contained. The sheet 
wrapping is secured around the body using a rope. It is important to avoid disfiguring the body when securing the rope and essential to avoid tying the rope tightly about the face as it may disfigure thus making identification efforts difficult. Moreover, rope tied tightly around the face is disrespectful to the decedent $[1,2]$.

To complete identification, a tag or label must be attached to the body with as much information as possible. This information should include the following: identification of the body performed by visual recognition (if identified, when and by whom) or by available documentation (e.g. driver's license); details of body discovery (address, location, position and date and time found); valuables and personal effects found with the body (e.g. clothing, wristwatch, jewelry); name and phone number of the person filling out the tag; type of contamination if any; and other casualties (living and dead) found nearby. Upon completion of the tag or label, each body must be placed in a separate disaster pouch or in plastic as described above and tied securely to prevent unwrapping. A second tag is attached with the information above to the outside of the body bag. If personal effects are found and thought to belong to a body, there is no guarantee of ownership, and thus personal effects must be placed in a separate container $[1,2]$.

Once the body has been properly tagged, it should be moved to a cool location, preferably with refrigeration. Bodies should never remain exposed to extreme heat or direct sunlight. The putrefaction process is both temperature- and exposure-dependent. Environmental temperature makes a significant difference in the speed of putrefaction. Table 1 shows an approximated putrefaction time scale dependent on temperatures and weather conditions which naturally can vary in different geographic locations [3]. All bagged bodies must be moved to the fatality collection area which must have security established to prevent looting of personal effects. A record must be kept with the number of bodies and location of each one of them.

Table 1 Speed of putrefaction of exposed human remains

\begin{tabular}{lll}
\hline & Summer & Winter \\
\hline Facially identifiable & Day 1 & Day 5 \\
Bloating & Day 2 & Day 2-6 \\
$\begin{array}{l}\text { Putrefaction/external maggots } \\
\begin{array}{l}\text { Collapse of face and abdomen/inter- } \\
\text { nal maggots }\end{array}\end{array}$ & Day 3 & Day 3-10 \\
$\begin{array}{l}\text { Skeletonizing } \\
\text { Dismemberment }\end{array}$ & Week 2 & Week 2-3 \\
\hline
\end{tabular}

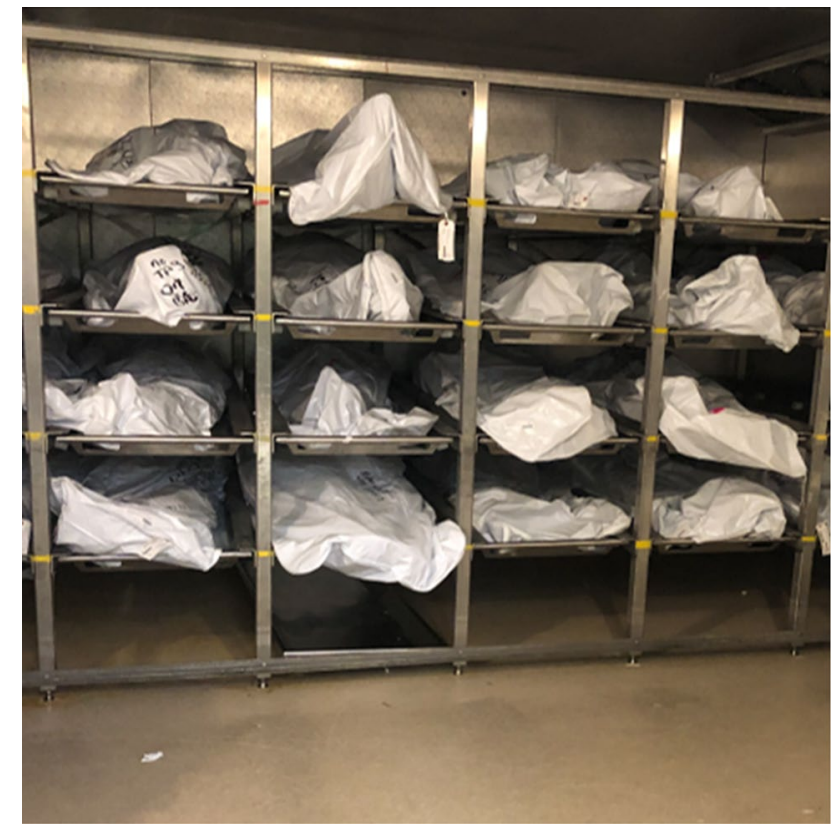

Fig. 1 Hospital morgue at its full capacity (Dr. Rapkiewicz personal archives)

\section{COVID-19 pandemic casualties}

The current pandemic of COVID-19 has turned into a mass casualty disaster of biological origin. COVID-19 is caused by severe acute respiratory syndrome coronavirus 2 (SARS-CoV-2), classified under hazard group-3 (HG3) pathogen by the Advisory Committee on Dangerous Pathogens (ACDP) [4]. Morgues are easily overwhelmed by a sudden surge in the number of dead bodies without any disposal plan in place [5, 6]. The COVID-19 pandemic has created such an event, rendering morgues inadequate at heights of the crisis. Cohabitants of those who are deceased are understandably unwilling to handle the decedent out of fear of contracting the disease. These and other challenges have resulted in the current pandemic taking on similarities to a natural environmental disaster where bodies require burial in mass graves [7]. The emotional suffering of decedent family members is only magnified by poor recordkeeping, resulting in an uncertain disposal location.

As the COVID-19 pandemic became a disaster with mass casualties, [8] even in countries where mass disasters are infrequent, communities found themselves overwhelmed with COVID-19 deaths. Before any crisis overwhelms first responders and resources, an emergency response plan must be established and activated early to ensure proper sanitation measures while handling the bodies for storage, as well as pre-processing prior to cremation 
or burial. Preparedness helps to avoid undignified management of bodies. When the number of deceased rises rapidly and the hospital morgues are at full capacity as shown in Fig. 1, hospitals use what is called a Body Collection Point (BCP). BCP is defined as a temporary refrigeration unit used to store decedents until transport is arranged (Figs. 2, 3, 4 and 5). BCPs allow a hospital to store a larger number of decedents until they can be released to funeral homes or until the OME takes possession. The purpose of a BCP is to emergently decompress hospital morgue systems and provide the facility time to respect the wishes of a decedent's family [9]. Our own institution, located in the New York metropolitan area, had nearly doubled the number of deceased patients during the COVID-19 pandemic, rising from 521 in 2019 up to 913 in 2020, with a peak in the month of April.

Management of the BCP is the responsibility of the hospital that cared for and declared death of the decedent or that received a body from the field. In a disaster such as that created by the pandemic, the BCP is considered an extension of the hospital's morgue. As such, the hospital takes responsibility for transportation of the deceased from patient care areas to the BCP. The hospital also takes responsibility for notifying families of the death and facilitates arrangements for final disposition. A morgue census for all cases stored in the BCP must be meticulously maintained. Hospitals must monitor refrigeration truck fuel levels as well as the temperature inside the $\mathrm{BCP}$ to ensure that storage remains within $37-44^{\circ} \mathrm{F}\left(3-7^{\circ} \mathrm{C}\right)$ range. Electricity, shelving, and body lifts also fall under hospital responsibilities.
At the height if the pandemic, hospital personnel not primarily responsible for patient care were reassigned to other areas in support of the increased need. These personnel were provided with training on donning and doffing and on how to handle and transport deceased due to COVID-19. A COVID19 death flowchart as shown in Fig. 6 was utilized.

Twenty-four-hour security must be ensured, and depending on the location of the BCP, this may include measures to ensure both privacy and security, such as installation of lighting elements or cameras and tents, or covered walkways. Thus, it was important to identify a suitable location for the BCP, involved an area away from neighboring residents to ensure proper privacy. Of note, the hospital is also responsible for the management of the deceased's personal effects.

Although hospitals are not required, they are encouraged to maintain at least two separate BCPs. The aim of this redundancy is to maintain a $\mathrm{BCP}$ for each type of decedent: $\mathrm{BCP} 1$ for cases pending funeral homes collection, which is usually imminent; and $\mathrm{BCP} 2$ for cases pending OME collection. In the event that only one BCP is established, cases that fall under OME jurisdiction must be stored in the hospital fixed facility morgue [1]. Examples of OME jurisdiction include any decedent that dies by suicide, homicide, accident, or suspicious circumstances. Fetal remains also fall within OME jurisdiction.

The hospital takes full responsibility for managing the BCPs until they are removed either by the funeral home or by OME (Fig. 6). The latter is the only time that the government is involved with the deceased patient. The OME is only
Fig. 2 Tents used as BCP placed in Central Park, New York City during the 2020 COVID-19 pandemic (Dr. Petrone personal archives)

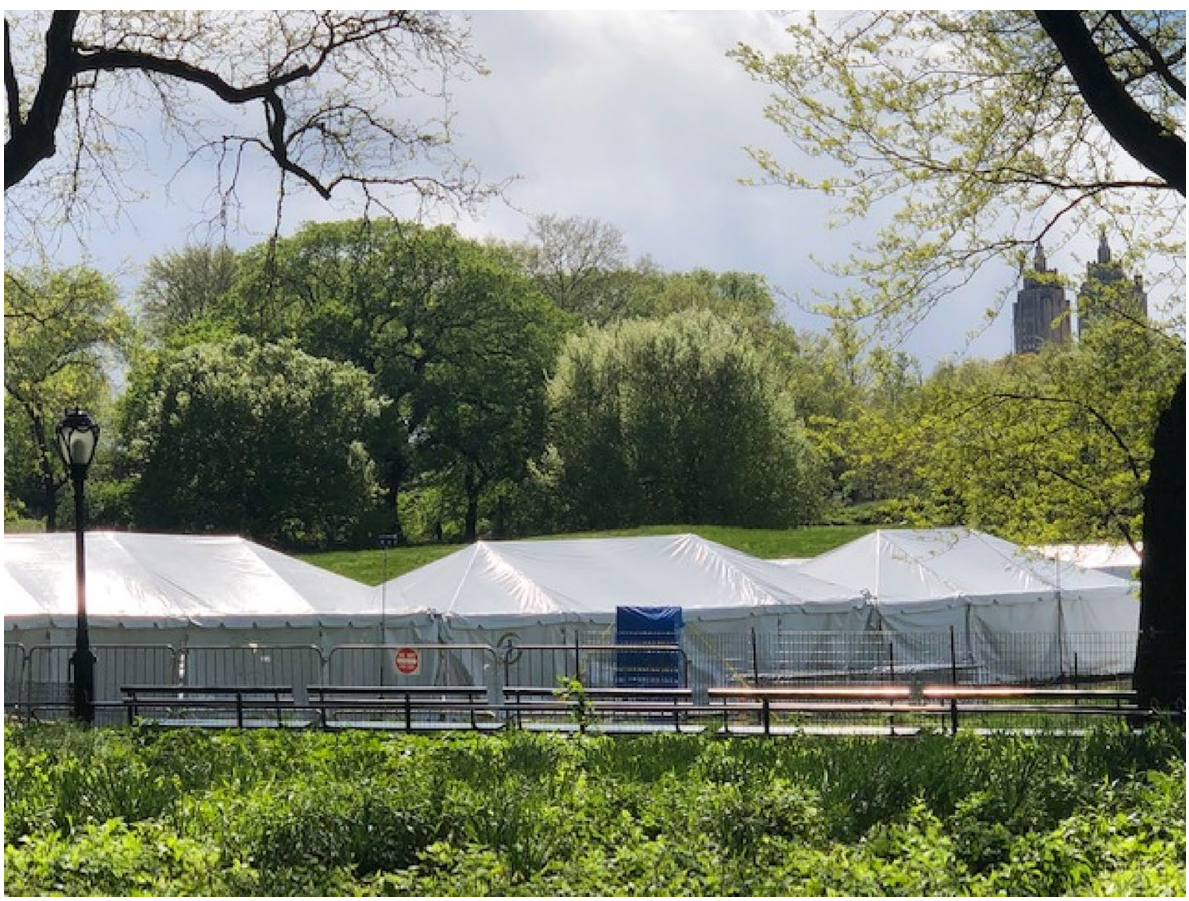


Figs. 3-5 Different types of refrigerated containers located at many medical institutions throughout New York metropolitan area during the 2020 pandemic, including our own (Dr. Petrone personal archives)
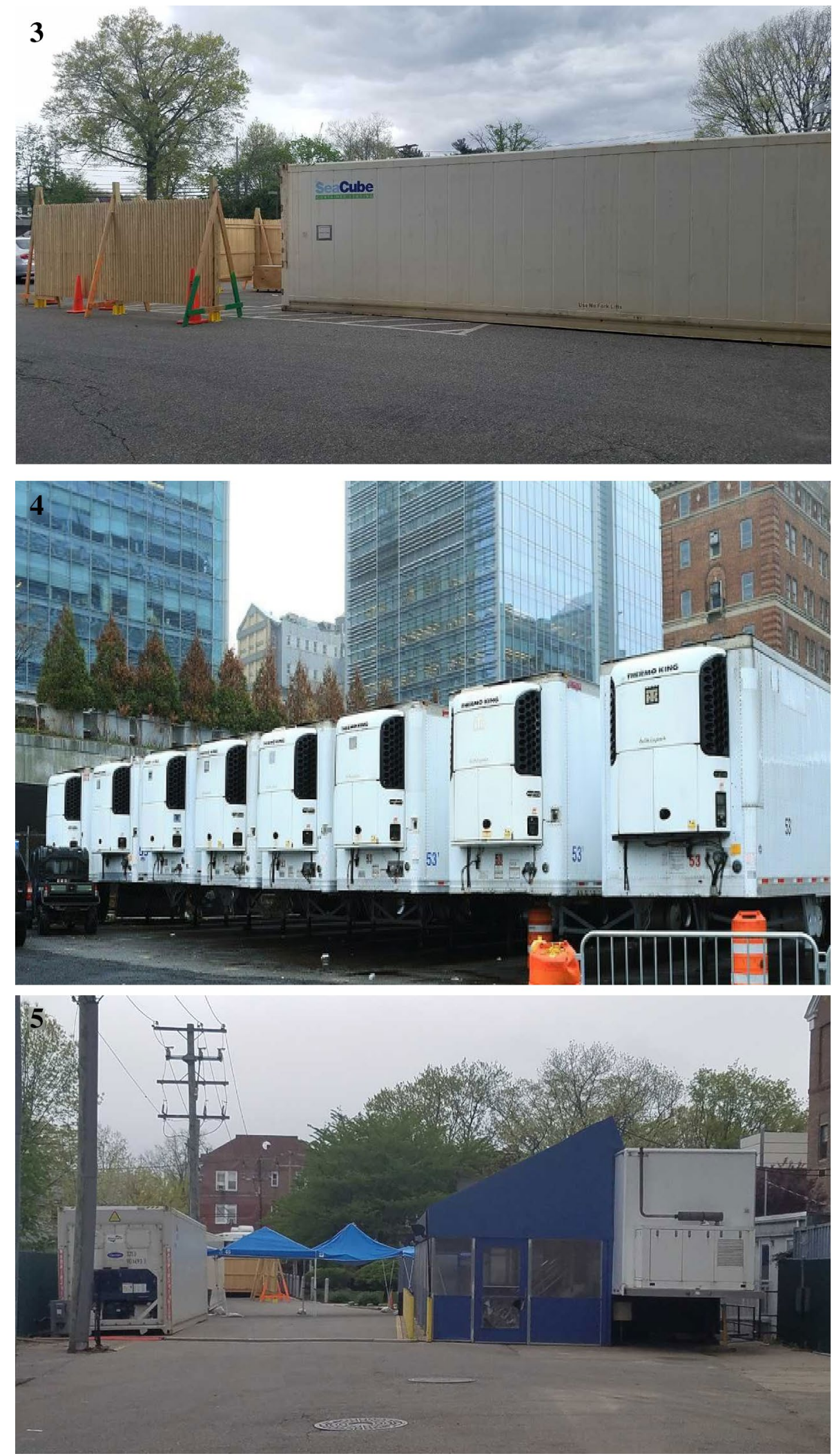

involved with cases where investigation into the cause of death is indicated. The government is also involved when a U.S. citizen dies overseas. The U.S. consular officials at the
Department of State work to transfer the remains to the US, under guidance from the Centers for Disease Control (CDC). COVID-19 is a quarantinable communicable disease, and 
Fig. 6 COVID-19 Death

Flowchart

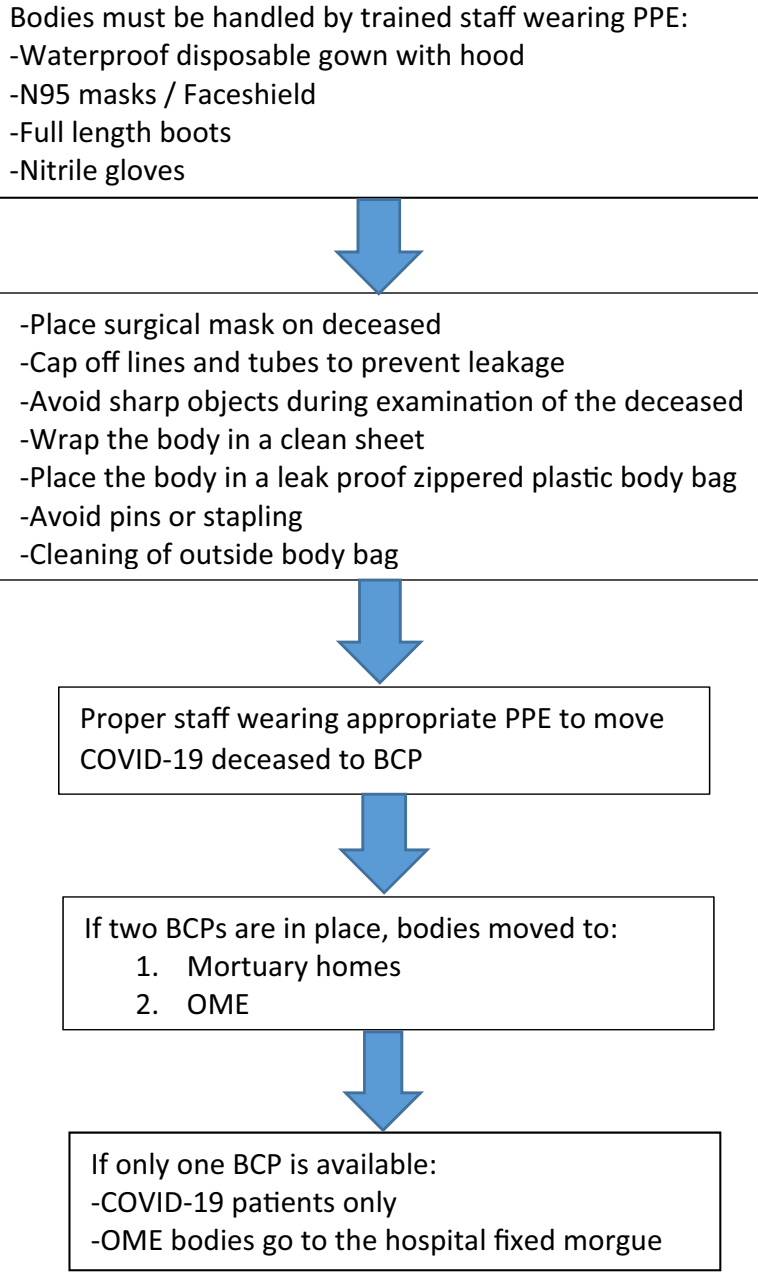

PPE: personal protective equipment; BCP: body collection point; OME: Office of Medical Examiner.

in the United States, the remains must meet the standards for importation as found in the Code of Federal Regulations. A decedent may be cleared and authorized for entry into the United States only under the following conditions: a) the remains are cremated; b) the remains are properly embalmed and placed in a hermetically sealed casket; or c) the remains are accompanied by a permit issued by the CDC Director. The CDC permit must accompany the human remains at all times during shipment. Permits for the importation of the remains of a person known or suspected to have died from a quarantinable communicable disease may be obtained through the CDC Division of Global Migration and Quarantine. CDC does not require an autopsy before the remains of a person who died overseas are returned to the United States. For patients dying stateside and not under the jurisdiction of the OME, care is taken to limit spread of the disease by ensuring that both the decedent and the operator are fully protected. Autopsies are limited and in fact, NYU Langone Hospital—Long Island was among the first institutes in the US to perform autopsies, under direction and guidance from the National Institute of Allergy and Infectious Diseases (NIAID).

Decedents should always be handled in a manner denoting respect, including the loading and unloading of bodies from the BCP. Bodies should always be placed face up and should never be stacked. They must remain properly positioned to allow for efficient storage: arranged on each side of the $\mathrm{BCP}$ leaving a center aisle for walking to facilitate the release of cases to funeral homes. As the $\mathrm{BCP}$ is nearing capacity and a request for retrieval of the entire $\mathrm{BCP}$ is prepared, only then should bodies be placed in the center walkway thus maximizing the storage of decedents. Body bags/human remains pouches should be properly labeled with both a wristband and a toe tag. A tag affixed to each 
body bag indicating the decedent's full name and medical record number (MRN) is standard. Only when the BCP is at capacity will it be retrieved by OME [10]. Of note, if no shelving has been installed, refrigeration truck capacity is roughly 45 decedents; with shelving, capacity approximates 80-100 decedents. Hospitals must also mobilize the space surrounding the $\mathrm{BCP}$ at the time of collection, including removal of surrounding privacy tenting or structures. Hospitals should request a replacement BCP, if needed. It is paramount that replacements be arranged to coincide with retrieval thus ensuring continuity of storage operations.

\section{Recommendations for management}

Before disposal, body identification and disease infection control/prevention measures are paramount [2]. As the identification of dead bodies due to COVID-19 will likely be well established, prevention and control of infection remains the most critical step. In this respect, the maintenance of personal hygiene including hand hygiene and proper donning and doffing of personal protection equipment (PPE) before and after handling of the dead body are strongly encouraged. However, in low-income and under-resourced countries, and even developed countries as seen in the current pandemic, the availability of trained staff and resources, such as PPE, chemicals used for sanitization, and puncture-proof body bags, may present major hygiene concerns.

The two most common methods of body disposal are cremation or burial. Because of financial considerations as well as the need to limit the spread of infectious fluids-cremation is the method recommended in low-income countries. However, international organizations have raised concerns over cremation of COVID-19 victims when this process is outside the religious beliefs of the community as it can cause social unrest [8].

Worldwide, countries facing mass death have been overwhelmed with both morgues and cemeteries running out of available space [11]. Immediate transportation to cremation or burial sites may prevent the overwhelming of morgue storage capacity, especially in low- and mediumincome countries which have limited morgue capacity to begin with. Key to maximizing morgue capacity is around the clock collection of bodies. In addition, importantly are the identification of other burial or cremation sites along with proper communication and coordination. During body transportation, it is of great importance that should body bags be reused, only disinfected body bags are utilized to prevent spread of infection as suggested by the World Health Organization and other international agencies [7, 12, 13].

Resources should be properly mobilized to ensure the dignity of the decedent, respect for the bereaved, and identification and traceability of deceased patient [13, 14]. Health care workers should be trained with respect to body handling, sanitation, and packaging. Additionally, training in methods to increase the capacity of cold storage, the assignment of stretchers for the dead within hospital premises, and the avoidance of unnecessary COVID-19 death autopsy requests will also be required. Training in the procurement of bulk supplies, such as sanitizers, PPE, and body bags, will also be beneficial.

Even though it seems the worst of the crisis has passed, plans must be created now to deal with future global disasters. A future pandemic, which stretches the capacity of the health care system, is certain to occur. Preparations must consider the safe, respectful storage and handling of the dead.

Acknowledgements To Dr. Amy Rapkiewicz for her courtesy photograph 1.

Author contribution Design: PP. Drafting of the manuscript: PP, DKJ, RJ, GB, CEMB. Critical revision: PP, DKJ, RJ, GB, CEMB.

\section{Declarations}

Conflict of interest Patrizio Petrone, D’Andrea K. Joseph, Ricardo Jacquez, Gerard Baltazar, and Collin E.M. Brathwaite declare that they have not conflict of interest.

Informed consent This study does not need an informed consent.

\section{References}

1. Department of Health, Hospital Authority, Food and Environmental Hygiene Department. Precautions for handling and disposal of dead bodies. https://www.chp.gov.hk/files/pdf/grp-guideline-hpic-precautions_for_handling_and_disposal_of_dead_bodies_en. pdf. Published February 2020. Accessed 28 Apr 2020.

2. Pan American Health Organization (PAHO). Management of dead bodies in disaster situations (disaster manuals and guidelines on disasters series, No 5). Washington, DC: PAHO; 2004.

3. Disaster and Community Services Program. Procedures to be followed for handling the dead. Los Angeles, CA: Los Angeles County Department of Coroner; 2020. (Accessed 7 Jul 2020).

4. Hanley B, Lucas SB, Youd E, Swift B, Osborn M. Autopsy in suspected COVID-19 cases. J Clin Pathol. 2020;73(5):239-42.

5. The New Humanitarian. Hard lessons from COVID-19 on looking after the dead. https://www.thenewhumanitarian.org/news-feature/ 2020/06/15/Coronavirus-Brazil-Mexico-Peru-Ecuador-dead-bodies-forensics-morgues-COVID19-ICRC. Published 2020, June 15. Accessed $20 \mathrm{Jul} 2020$.

6. The Conversation. Overloaded morgues, mass graves and infectious remains: How forensic pathologists handle the coronavirus dead. https://theconversation.com/overloaded-morgues-massgraves-and-infectious-remains-how-forensic-pathologists-handlethe-coronavirus-dead-135275. Published 2020, April 9. Accessed $20 \mathrm{Jul} 2020$

7. World Health Organization. Infection Prevention and Control for the safe management of a dead body in the context of COVID-19 Interim guidance. 2020, March 24:1-6. 
8. International Committee of the Red Cross. COVID-19: Authorities must urgently plan ahead to ensure the dead are properly handled. International Committee of the Red Cross. https://www. icrc.org/en/document/covid-19-authorities-must-urgently-planahead-ensure-dead-bodies-are-properly-handled. Published April 22, 2020. Accessed 28 Apr 2020.

9. Office of Chief Medical Officer. Hospital body collection point: guide for COVID-19, version 3.0. New York City, NY : OCME; 2020. (Accessed 24 Apr 2020).

10. Office of Chief Medical Officer. Healthcare facility body collection point: request for retrieval guide. New York City, NY : OCME; 2020. (Accessed 9 Apr 2020).

11. Business Insider. In Wuhan, China, where the outbreak began, funerals, burials and other related activities involving the corpses of deceased victims were banned months ago. https://www.busin essinsider.in/science/news/sobering-photos-reveal-how-count ries-are-dealing-with-the-dead-left-by-the-coronavirus-pandemic/ articleshow/75128388.cms. Published April 13, 2020. Accessed 3 May 2020.

12. Great Britain, Health and Safety Executive, Stationery Office (Great Britain). Managing infection risks when handling the deceased: guidance for the mortuary, post-mortem room and funeral premises, and during exhumation. Norwich: The Stationery Office; 2018.

13. PHA Canada. Interim guidance: Management of mass fatalities during the coronavirus disease (COVID-19) pandemic. https:// www.canada.ca/en/public-health/services/diseases/2019-novelcoronavirus-infection/guidance-documents/management-massfatalities.html. Published April 25, 2020. Accessed 30 Apr 2020.

14. World Health Organization. Mass casualty management systems: Strategies and guidelines for building health sector capacity. Geneva: WHO Press; 2007. 